\title{
DIREITO E VIDA: UMA RELAÇÃO VIOLENTA
}

\author{
LAW AND LIFE: A VIOLENT RELATION
}

\section{RESUMO}

Neste artigo, tratar-se-á a problematização apresentada por Walter Benjamin (1892-1940) acerca da relação entre vida e direito. Para o autor berlinense, o direito, longe de ser uma elaboração racional digna de culto, carrega consigo um caráter de instrumentalização que lhe possibilita subjugar a vida e dominála. Assim, apresentaremos as teses precipuamente contidas no texto sobre a violência, datado de 1921, as quais nos apontam o caráter mítico do direito e o caráter violento de seus contratos. Apresentar-se-á, também, a tese defendida pelo autor que coloca meios puros na política como forma de agir não violento. Conclui-se que a vida autêntica é histórica, para além da "mera vida" orgânica e de toda e qualquer representação jurídica ou violenta do direito.

Palavras-chave: política; mito; direito; violência; linguagem.

\begin{abstract}
This article will be dealing with the problematization presented by Walter Benjamin (1982-1940) about the relation between life and law. For the Berlin author, law, far from being a rational elaboration worthy of worship, carries within itself a character of instrumentalization, from which it enables the law to subjugate life and to dominate it. Thus, we will present the theses that are essentially demonstrated in the text about violence dating back to 1921, which point out to the mythical character of the law and the violent nature of its contracts, as well as the thesis defended by the author in which he indicates pure means in politics as a form of nonviolent action. Concluding that authentic life is historical, beyond organic "mere life", and any or all legal or violent representation of law.
\end{abstract}

Key words: policy; mith; law; violence; language.

\footnotetext{
${ }^{1}$ Pós-Graduando em Direito Penal (lato sensu) pela Centro Universitário Leonardo da Vinci (UNIASSELVI).

CV Lattes: http://lattes.cnpq.br/5255861374881199
} 


\section{A existência de meios puros na política}

O presente artigo parte do questionamento de Benjamin, no ensaio Para uma crítica da violência (1921), sobre se existiriam meios não violentos de exercício do poder. Benjamin responde-nos incisivamente: "sem dúvida". Esses meios não estariam a cargo de fins prédeterminados, mas seriam independentes em si mesmos. O autor alude, de início, à ressalva de que não seria possível a existência de meios não violentos por intermédio de um contrato, pois este prevê sempre a possibilidade do recurso à violência, mesmo que ela não esteja explícita no contrato, uma vez que o poder [Macht] que garante o cumprimento do contrato é de origem violenta. De uma forma ou de outra, aquele que se sentir prejudicado em um acordo contratual poderá recorrer ao poder jurisdicional do Estado, que age com sua força de lei para o cumprimento dos termos acordados. Então, um meio não violento excluiria, por princípio, a instituição do contrato, pois "a origem de qualquer contrato aponta para a violência" (BENJAMIN, 2011, p. 137), seja em sua origem, seja em seu desfecho.

Antes de adentrarmos a discussão realizada por Benjamin sobre meios não violentos, ou seja, meios puros [reinen Mittel], e sua possibilidade de mediação política, cabe ressaltar a decepção pessoal do autor com relação ao parlamentarismo da época, o qual foi aclamado e chegou ao poder por meio de forças revolucionárias, mas perdeu a consciência de tal fato, entrando em decadência:

Falta a esses o senso para a violência instauradora do direito, que neles está representada; assim, não é de estranhar que não consigam tomar decisões que sejam dignas dessas violências, mas cultivem, com a prática dos compromissos, uma maneira supostamente não violenta de tratar assuntos políticos. (BENJAMIN, 2011, p. 137)

Ao aceitar "compromissos", o parlamento inclui-se nas mesmas condições violentas de um contrato, pois o compromisso pressupõe uma força exterior, coercitiva, que o impele a cumprir. Portanto, o parlamentarismo não pode ser considerado um meio não violento para solução de conflitos, apesar de o ideal alemão ter sido a busca de uma representação dos interesses populares de forma pacífica. Veja-se:

Essa contradição [...] de uma República de Weimar marcada por tradições monarquistas se apresentara desde 1919 ao espírito de muitos alemães. Ela era tão evidente que o governo que deveria representar o regime republicano nada mudara na alta administração 
e continuava utilizando funcionários e oficiais do regime imperial. Todas as greves, motins e levantes populares seriam reprimidos com um rigor impiedoso. (RICHARD, 1988, p. 57)

Assim, como bem afirmara Derrida (2010, p. 110-111), “os parlamentos vivem no esquecimento da violência da qual nasceram. [...] O parlamentarismo está, portanto, na violência da autoridade e na renúncia do ideal".

Afastando-se da análise da esfera do direito público, ao menos por ora, Benjamin inicia sua investigação por meios puros na esfera da vida privada, localizando elementos subjetivos desses meios e elencando-os como "cultivo do coração: cortesia do coração, inclinação, amor à paz, confiança", termos de influência flagrante no judaísmo. Em sua forma objetiva, afirma Benjamin, seriam encontrados por toda parte onde há meios puros do entendimento, um meio não violento que deve passar pela "via das coisas" - isto é, mediado. Podemos encontrá-los objetivamente na esfera da linguagem, mais especificamente na técnica do diálogo como "técnica de civilidade do entendimento" (2010, p. 139), capacidade de resolução de conflitos sem recurso à violência - concepção que se assemelha muito à "teoria da ação comunicativa", posteriormente elaborada pelo filósofo Jürgen Habermas, também integrante da Escola de Frankfurt, uma vez que a ação comunicativa, para este, intenta uma compreensão de condições universais de produção de enunciados que visem ao entendimento mútuo, ao consenso, de forma não coercitiva. ${ }^{2}$

Os elementos puros da linguagem estão disponíveis às pessoas que buscam um acordo mútuo, e essa esfera do entendimento ${ }^{3}$ possibilita o bom relacionamento entre os homens e, consequentemente, destes para com o mundo. Essa compreensão deve-se ao conceito de linguagem para Benjamin, o qual difere Mittel e Medium. O primeiro alude a um caráter instrumental da língua (que, como todo instrumento, pode ser manipulada), a um comunicar-se "através da" língua; o segundo prevê a comunicação "na língua”. Veja-se, a esse respeito, a concepção benjaminiana no ensaio Sobre a linguagem em geral e sobre a linguagem do homem, datado de 1916:

Dito de outra maneira, a língua de uma essência espiritual é imediatamente aquilo que nela é comunicável. Aquilo que é comunicável em uma essência espiritual é aquilo no que se comunica; o que quer dizer que toda língua se comunica a si

\footnotetext{
${ }^{2}$ Veja-se HABERMAS, J. Teoria do Agir Comunicativo: racionalidade da ação e racionalização social. Tradução de Paulo Astor Soethe. São Paulo: WMF Martins Fontes, 2012. v. 1.

${ }^{3}$ Essa é esfera da linguagem em que é possível o entendimento, pois é dotada de meios puros, não violentos, prevalecendo o acordo mútuo.
} 
mesma. Ou melhor: toda língua se comunica em si mesma. Ela é, no sentido mais puro, o meio [Medium] da comunicação. (BENJAMIN, 2011, p. 53)

Valemo-nos também da observação de Derrida (2010, p. 118), que afirma:

Esta [linguagem] não é um meio visando um fim (uma coisa ou conteúdo significado, ou um destinatário), ao qual ela deveria adequar-se corretamente. Essa crítica do signo era, então, também política: a concepção da linguagem como meio e como signo seria "burguesa". (DERIDA, 2010, p.18)

A política também tem seu exemplo próprio de mediação de conflitos, a saber, a diplomacia. Benjamin nota que a tarefa de um diplomata segue de maneira análoga os mesmos ditames do entendimento (esfera da linguagem) entre pessoas privadas. Não há leis impositivas com força normativa - sequer diretrizes reguladoras - que regem os acordos diplomáticos, a não ser o objetivo de afastar os conflitos de forma pacífica. Uma tarefa "delicada", situada para além dos tribunais internacionais de arbitragem, para além de "toda ordem do direito e, portanto, de toda violência" (BENJAMIN, 2011, p. 145).

Isso se deve ao fato de a esfera da linguagem (da compreensão mútua) ser inacessível à violência, pois aquela é imediata [Medium], inter-relacionando-se consigo mesma. Por exemplo: houve um tempo em que não havia punições para a mentira, pois em princípio o direito estaria preocupado somente em suprimir possíveis afrontas à sua ordem. Somente tardiamente, por medo dos efeitos possíveis que poderiam vir a ocorrer por parte das "vítimas da mentira", o direito institui uma punição para tal e para o logro, pois "o direito romano e o antigo direito germânico não os sancionam” (DERRIDA, 2010, p. 114). O direito busca punilos não por moralidade, mas por temor a uma possível rebelião contra a violência/o poder mantenedor vigente.

Benjamin nota a partir desse temor, além da própria deterioração da esfera do direito, "um minguar dos meios puros" (2011, p. 140), uma vez que o direito suprimiu a possibilidade de meios puros ao adentrar o âmbito da linguagem; ao querer exercer controle sobre os discursos humanos, deixou evidente que ele mesmo não é absoluto e tende a ceder sob pressão, tal como ocorre no direito à greve e no caso do "grande criminoso", que já expuseram essa fragilidade.

Isso manifesta também a decadência fatal do Estado: ao interferir nessa esfera, buscando controlar a veracidade dos discursos pessoais, ignora os limites existentes entre público e privado, entre coletivo e individual. Ironicamente, Benjamin (2011, p. 140) afirma: "Como esse medo entra em conflito com a própria natureza violenta do 
direito, que vem das suas origens, esses fins [de adentrar a esfera da linguagem] são inadequados para os meios legítimos do direito". Expõe-se, assim, a origem violenta (mítica) do direito.

Passar-se-á, agora, à exposição dos argumentos apresentados pelo autor sobre a origem mítica (e, por consequência, violenta) do direito, e como ela afeta a vida dos indivíduos, sujeitos de (ao) direito.

\section{Fundamento mítico do direito}

Pois o direito positivo, quando consciente de suas raízes, com certeza reivindicará reconhecer e fomentar o interesse da humanidade na pessoa de cada indivíduo. Ele enxerga tal interesse na apresentação e na manutenção de uma ordem de destino. (BENJAMIN, 2011, p.133)

Considerando-se que Benjamin afirma que o direito se apresenta como uma ordem do destino, sendo este descendente direto do conceito de mito, passar-se-á à apresentação de tais conceitos. Para entender a reflexão de Benjamin sobre o mito, chave para a compreensão de sua filosofia, é necessário analisar a correlação entre mito e destino contidas no ensaio Destino e caráter (1916), o qual contém "a primeira formulação mais acabada do conceito de destino" (CHAVES, 1994, p. 16). Deve-se partir de uma concepção segundo a qual a ideia de destino estaria ligada, necessariamente, ao caráter em uma relação de causalidade:

[...] se, por um lado, o caráter de uma pessoa, isto é, também a sua maneira de reagir, fosse conhecido em todos os seus pormenores, e se, por outro, os acontecimentos do mundo fossem conhecidos nos domínios em que atingem esse caráter, então poderia dizer com exatidão tanto o que aconteceria a esse caráter quanto o que seria realizado por ele. Ou seja, seu destino seria conhecido. (BENJAMIN, 2010, p. 89, grifo nosso)

Essa relação é tida por Benjamin como arbitrária, desconsiderando a diferença própria ao sistema de sinais de cada um, pois o caráter ${ }^{4}$ está delimitado pelo corpo, enquanto o destino abarca os sinais corpóreos e, para além destes, os dos fenômenos da vida exterior. Assim,

\footnotetext{
${ }^{4}$ Em Aristóteles, tem-se a definição de que "caráter é aquilo que revela determinada deliberação; ou, em situações dúbias, a escolha que se faz ou se evita" (2004, p. 44).
} 
qualquer afirmação que resulte numa confirmação de interdependência entre esses dois conceitos leva a uma conexão do "caráter" ao ético e do "destino" ao religioso.

Benjamin (2011, p. 92) afirma que "de tais domínios eles devem ser banidos, por meio da revelação do erro que para lá os transportou", pois com essa relação, "de fato, atrelando-se o domínio do destino ao religioso, acaba-se por estabelecer uma outra conexão, não menos arbitrária: entre destino e culpa" (CHAVES, 1994, p. 17). Assim, os casos que resultam em infelicidade seriam, pois, "uma resposta dos deuses", ou frutos de uma "dívida religiosa". Benjamin nota que falta a essa concepção o "conceito de inocência"; assim, recorre aos gregos, segundo os quais a felicidade não está relacionada, de fato, à confirmação de uma vida inocente, mas ao endividamento "pesado" da hybris ${ }^{5}$. Logo, o destino não estaria, segundo os gregos, atrelado às ideias de felicidade ou infelicidade, pois "a felicidade é, muito mais, o que liberta aquele que é feliz das cadeias do destino e da rede do seu próprio destino" (BENJAMIN, 2010, p. 92).

O destino pode ser considerado uma ordenação que abarca culpa e infelicidade e, portanto, não pode pertencer à esfera do religioso - apesar de o conceito de culpabilidade sugeri-lo, valorizando culpa e infelicidade e excluindo inocência e bem-aventurança. Tal conceito de destino é determinante e inexorável. Benjamin procura, então, deslocar o conceito de destino a sua esfera correspondente, uma vez que esta não pode ser a do religioso:

Cabe então procurar um outro domínio, no qual única e tão somente a infelicidade e a culpa são válidas; uma balança, na qual bem-aventurança e inocência se encontram demasiado leves e se elevam no ar. Essa balança é a do direito. (BENJAMIN, 2011, p. 93)

Ao se revelar que o conceito de destino está ligado à esfera do direito, revela-se consequentemente que este último correlaciona-se com outra esfera: a do "mito". O direito funda as leis do destino ligando-as à vida humana, a saber, as leis de infelicidade e de culpa. Como observa Chaves (1994, p. 18), “assim, se hoje consideramos que o destino pertence ao domínio do religioso é porque, no decorrer da história, houve uma inversão de tal monta que os homens 'confundiram' direito com justiça". Essa "confusão" deve-se ao fato de que se acreditou que o direito seria algo de mais bem elaborado, mas, como Benjamin afirma em sua crítica da violência: "longe de inaugurar uma esfera mais pura, a manifestação mítica da violência mostra-

\footnotetext{
5 "Violação da norma da medida, ou seja, dos limites que o homem deve encontrar em suas relações com os outros homens, com a divindade e com a ordem das coisas." (ABBAGNANO, 1998, p. 520)
} 
se, em seu núcleo mais profundo, idêntica a toda violência do direito" (2010, p. 150). Veja-se, em suma, o que Chaves (1994, p. 18-19) afirma sobre tal crítica:

\begin{abstract}
Sua crítica do direito, portanto, atinge dois alvos ao mesmo tempo: ela serve tanto para desmascarar a "troca enganosa" que nos faz confundir direito e justiça quanto nossa crença de que o direito é uma elevada elaboração racional, uma conquista inelutável da "civilização", que nele nada mais há de mítico, que o direito, enfim, venceu a "luta contra os demônios".
\end{abstract}

Longe de ser uma conexão do acaso ou arbitrária, o direito desde seu início funda sua teoria em três pilares: destino, culpa e expiação - o destino como fluxo inexorável, a vida culpável (culpabilizada) e sua expiação necessária. O direito não tem em seu fundamento a justiça, enganando a todos ao se afirmar como aquilo "que inaugurou a vitória sobre os demônios" (BENJAMIN, 2010, p. 93) - entendendo-se "demônios" como as forças do mito. Benjamin não vê no direito tal "vitória", mas na tragédia grega, que pela primeira vez "fez emergir [...] a cabeça do gênio das névoas da culpa, pois na tragédia o destino demoníaco é interrompido". Isso não quer dizer, contudo, que Benjamin note no "herói da tragédia" uma pureza a ser admirada, pois esta ainda está ligada à sua infantilidade moral, daí sua inocência; tampouco quer dizer que o herói subverta o direito, libertando-se da culpa - o herói grego, porém, causa a interrupção ${ }^{6}$, mesmo que momentânea, do destino inexorável.

O destino, relação de culpa dos seres vivos, mostra-se "quando se considera a vida de um condenado, no fundo, uma vida que primeiro foi condenada e por isso tornou-se culpada"; “o direito não condena à punição, mas à culpa” (BENJAMIN, 2010, p. 94). Isso se deve a uma visão simplista da vida, a qual considera somente a constituição natural do vivente, uma vida simples (mera vida), vida entre outras vidas que, por sua "aparência", "participa da culpa natural e da infelicidade". Assim, o juiz condena, cegamente dita um "destino" no qual a "vida" em todo seu sentido não é atingida, mas somente a mera vida, mundana e corpórea.

Um último aspecto, não menos importante, sobre o destino (e consequentemente sobre o mito) abordado por Benjamin é o de temporalidade. O vínculo entre culpa e vida é temporal, e essa temporalidade é "parasitária", ou seja, nela não há nada de "presente”, podendo ser igual a qualquer tempo que já passou e tornando-se dependente de um tempo em que houve uma "vida superior", não ligada à vida natural. Difere-se, assim, de outras temporalidades: a da redenção (messiânica), a da música e a da verdade.

\footnotetext{
6 "as chacoalha e mistura" (BENJAMIN, 2010, p. 94)
} 
Notou-se até aqui que Benjamin analisa o conceito de mito a partir de sua correlação com o conceito de destino e as relações deste com as práticas jurídicas, deslocando tal conceito da esfera do religioso para o natural (profano) e atribuindo-lhe a noção de temporalidade que lhe é própria, a parasitária. Tais aspectos também estão presentes no conceito de direito, desde seu fundamento mais elementar.

\section{Mera vida, vida meramente biológica}

Conforme o abordado, o direito impõe-se como se fosse o próprio destino, reconhecendo a vida como simples e mera, vida entre outras vidas. Analisar-se-á, neste momento, o que Benjamin compreende como vida e de que maneira esta distingue-se da mera vida (vida orgânica). Note-se, previamente, que a palavra "vida" [Leben] apresenta-se de maneira ambígua. Agamben traduziu o conceito "das Blosse Leben" a partir do ensaio benjaminiano sobre a violência como "vida nua"; entretanto, nu [nackt] e mero [bloss], apesar de próximos, possuem certa diferenciação, pois “o adjetivo bloss significa 'mero', 'simples', 'sem nenhum suplemento' [...], [enquanto] nackt designa a nudez de uma criança que sai do corpo de sua mãe" (GAGNEBIN, 2011, p. 151, recortes e inserções nossas).

Os textos benjaminianos de juventude remetem a uma "metafísica" particular do autor, segundo a qual a "mera vida" não tem valor por si só, enquanto mera existência biológica sendo o sangue símbolo de sua existência mortal -, mas somente em uma esfera superior e histórica. Assim, Benjamin opõe o natural ao histórico; somente uma vida histórica pode ser justa e fazer justiça à existência humana:

É falsa e vil a afirmação de que a existência teria um valor mais alto do que a existência justa, quando existência significar nada mais do que a mera vida - e é esse o sentido do termo na referida reflexão. Mas a proposição contém uma verdade poderosa, se "existência", ou melhor, "vida" [...] significar a condição de composto irredutível do "homem". Se a proposição quer dizer que o não-ser do homem é algo de mais terrível do que o ainda-não-ser (portanto, necessariamente mero, do homem justo). (BENJAMIN, 2011, p. 154, grifo nosso)

Esse composto irredutível pode ser compreendido pela tríade vida terrena (biológica), vida incorpórea e continuação da vida ("pervivência”). Quanto ao primeiro termo, Benjamin contesta o dogma moderno de sacralidade da vida, pois este intenta 
sacralizar a mera vida, destituída de valor, de sentido, por sua natureza biológica. Benjamin questiona esse dogma, pois, se assim fosse, o que tornaria o homem biológico essencialmente diferente de outras formas de vidas existentes? Mesmo que outras formas de vida fossem sagradas, "não a seriam pela mera vida nelas, nem por estarem na vida" (BENJAMIN, 2011, p. 154). Afirma ainda que, por se tratar de um dogma recente, poder-se-ia compreender o motivo do erro ao se afirmar a sacralidade de uma vida simples (mera) aludindo-se à necessidade de uma investigação desse dogma - realizada por Giorgio Agamben no livro O poder soberano $e$ a vida nua. Cumpre colocar ressalvas quanto à interpretação do filósofo italiano, que seguiu uma linha diferente da de Benjamin, pois, se a vida humana for sacra, não é por seu estado de vida natural (sujeito a intervenções de diversas formas), mas por algo que transcende essa forma de vida. Para Agamben, a investigação sobre a sacralidade da vida segue o plano da biopolítica contemporânea, enquanto para Benjamin trata-se de uma tese falha que pretende negar, de forma absoluta, a possibilidade de uso da violência sob quaisquer circunstâncias - até mesmo em uma situação de preservação da vida, como no caso da legítima defesa. Tal argumento supõe uma certa "sacralidade da vida" por ela mesma (enquanto blosse Leben). Veja-se:

A apresentação desse ponto de vista é uma das tarefas da minha filosofia moral e, nesse sentido, o termo "anarquismo" pode muito bem ser usado para descrever uma teoria que nega o direito de usar violência, como tal, a toda instituição, comunidade humana ou individualidade que quer reivindicar o monopólio sobre ela [violência] ou, de qualquer forma, reivindica o direito para si mesmo de qualquer ponto de vista, mesmo que apenas como um princípio geral, em vez de respeitá-lo em casos específicos como um dom concedido por um poder divino, como poder absoluto. (BENJAMIN, 2004, p. 233, tradução nossa)

Nesse texto, escrito por volta de 1920 e intitulado Das Recht zur Gewaltanwendung (em português "O direito de usar a força"), publicado na revista Notas para um socialismo religioso (Blatter fur religiosen Sozialismus), Benjamin, através de um anarquismo confesso, posicionase contra qualquer tentativa de centralização do poder violento exercido contra a vida por parte de qualquer instituição, seja ela pública ou privada. Tal texto está em consonância com outros da mesma época.

Em A tarefa do tradutor (1921), ensaio escrito no mesmo ano que Para uma crítica da violência, Benjamin afirma que "o fato de que não seja possível atribuir vida unicamente à corporeidade orgânica foi intuído mesmo por épocas em que o pensamento era dos mais preconceituosos" (BENJAMIN, 2011, p. 104). Nota-se claramente o pensamento metafísico aqui existente. Para que seja possível compreender a segunda forma de vida, cabe salientar que Benjamin não afirma a existência de um dualismo alma- 
corpo, mas a configuração histórica e cultural da vida, na qual ela excede a vida simples e tornase vida autêntica. A realização da vida justa pode-se chamar de vida autêntica, pois a justiça só é possível em um plano histórico, e não na natureza: "pois é a partir da história (e não da natureza - muito menos de uma natureza tão imprecisa quanto a sensação ou a alma) que pode ser determinado, em última instância, o domínio da vida" (BENJAMIN, 2011, p. 104).

Considerando-se tudo aquilo que a vida possui de história é que o conceito de vida encontra seu reconhecimento, pois a história não constitui apenas um contexto da vida, mas a esfera em que a vida se reconhece e se torna autêntica. A partir disso, pode-se compreender a terceira forma de vida, a "pervivência", o continuar vivendo mesmo após a vida, conceito que Benjamin utiliza para explicar como a obra de arte mantém o autor que a criou "vivo" por sua obra, mesmo após sua morte. O próprio autor afirmara em suas fugas, em meio à perseguição nazista, que sua vida era menos importante que os escritos que levava consigo. Portanto, "pervivência" define-se por aquilo que sobrevive à mortalidade da vida, os atos que permanecem na história - como as obras de um autor, os hábitos tradicionais em uma família, as construções físicas e intelectuais, entre outras obras propriamente humanas que "sobrevivem" ao tempo.

Uma vez apresentadas as concepções de vida para Benjamin, passar-se-á à análise da relação entre vida e direito.

\section{Vida e Direito}

Como já exposto neste trabalho, o direito culpabiliza a "mera vida" para subjugá-la, com a intenção de alcançar seus fins e, principalmente, seu próprio fortalecimento. A mera vida é, portanto, o subsídio mítico contraposto à vida histórica. Para se compreender melhor essa oposição, recorrer-se-á a Jeanne Marie Gagnebin, em sua apresentação sobre Benjamin:

[...] na esteira da tradição judaica, Benjamin coloca, do mesmo lado, história e religião (porque religião implica a resposta de um sujeito humano ao Sujeito supremo; portanto, a responsabilidade humana), em declarado antagonismo com o mito e a natureza, de outro [...] a crítica do mito não é apenas uma crítica de certo momento vivido pela humanidade, mas significa a crítica de uma concepção de vida e de destino que sempre ameaça, sob formas diversas, as tentativas de agir histórica e livremente. (GAGNEBIN, 2011, p. 9) 
O direito impede a vida de viver livremente enquanto vida autêntica; contudo, a mera vida, por si só, encontra-se em um ambiente de anomia, tornando-se alvo de qualquer infortúnio possível, sendo definida, segundo o antigo pensamento mítico, como a portadora natural da culpa. Assim, segundo Castor Mari Martín Bartolomé Ruiz (2013):

No âmbito da mera vida (bloß Leben), o direito permanece desativado num duplo sentido. Ela é uma mera vida que existe sem direitos ou fora do direito, vive desprotegida sob a ameaça de qualquer violência e sem direito para se defender. Mas, paradoxalmente, o direito não é a garantia última da vida. A vida, que necessita do direito para se proteger contra a violência, tem que se proteger também da violência do direito. O direito tende a normatizar a vida, normalizá-la na imposição da lei e da norma. (RUIZ, 2013, p. 61)

Uma vez que a temporalidade do direito é parasitária, ela sempre impele à eterna repetição, à busca de um tempo anterior e superior, inatingível. A realização de uma vida autêntica torna-se inviável se não houver uma forma de se desprender das amarras do direito. Sempre haverá a correlação entre vida e culpa e a naturalização de ambas, entrave para uma verdadeira história. "A partir de Benjamin, não a vida, mas a história é política" (BARBOSA, 2013, p. 157), e o que torna a vida autêntica, política, deixando de ser "mera", "simples", é ser sujeito-histórico - longe de ser a tarefa de "libertação" simples, o que leva Benjamin a afirmar ser possível por meio de um poder divino (mas que seria irreconhecível aos olhos dos homens) ou de uma violência revolucionária [revolutionäre Gewalt] - de forma pura, acessível aos homens em particular, por meio do entendimento linguístico, por meios puros na linguagem que escapam à dominação do direito e subsistem a seu poder mítico. 
Referências

ABBAGNANO, Nicola. Dicionário de Filosofia. São Paulo: Martins Fontes, 1998.

AGAMBEN, Giorgio. Homo sacer - o poder soberano e a vida nua I. 2 ed. Belo Horizonte: Editora UFMG, 2010.

ARISTÓTELES. Poética. In: Aristóteles, Coleção Os Pensadores. São Paulo: Editora Nova Cultural, 2004. p. 37-75.

BARBOSA, Jonnefer F. A crítica da violência de Walter Benjamin: implicações histórico-temporais no conceito de reine Gewalt. In: Rev. Filos., Aurora, Curitiba, v. 25, n. 37, p. 151-169, jul./dez. 2013.

BENJAMIN, Walter. Escritos sobre mito e linguagem. Organização, apresentação e notas de Jeanne Marie Gagnebin e tradução de Susana K. Lages e Ernani Chaves. São Paulo: Duas Cidades: Editora 34; Duas Cidades, 2011.

Reflexões sobre a criança, o brinquedo e a educação. Tradução de Marcus Vinicius Mazzari. 2 ed. São Paulo: Editora 34; Duas Cidades, 2009.

. The right to use the force. Tradução de Rodney Livingstone. In: Selected Writings - Volume I (1913-1926). Massachusetts: Harvard University Press, 2004, p. 231-234. . Zur Kritik der Gewalt. In: Walter Benjamin: Gesammelte Schriften II. Edição de Rolf Tiedmann e Herman Schweppenhauser. Frankfurt am Main: Suhr Kamp, 1991. p. 179203.

CHAVES, E. Mito e política: notas sobre o conceito de destino no “jovem” Benjamin. In: Trans/form/ação, São Paulo, v. 17, p. 15-30, 1994.

DERRIDA, Jacques. Força de lei: o fundamento místico da autoridade. Tradução de Leyla Perrone-Moisés. 2 ed. São Paulo: Editora WMF Martins Fontes, 2010.

GAGNEBIN, J. M. (Org.). Apresentação. In: BENJAMIN, W. Escritos sobre mito e linguagem. São Paulo: Editora 34; Duas Cidades, 2011. p. 7-11.

JACOBSON, Eric. Metaphysics of the profane: the political theology of Walter Benjamin and Gershom Scholem. New York: Columbia University Press, 2003.

RUIZ, Castor Bartolomé. Os paradoxos da sacralidade da vida humana: questões éticopolíticas do pensamento de W. Benjamin e G. Agamben. In: Rev. Filos., Aurora, Curitiba, v. 25, n. 37, p. 57-77, jul./dez. 2013.

SELINGMANN-SILVA, Márcio. Walter Benjamin: o estado de exceção entre o político e o estético. In: Outra travessia. Revista de Literatura, n. 5, 2 
semestre/2005. Curso de Pós-Graduação em Literatura. Centro de Comunicação e Expressão. UFSC, p. 25-38.

TOCHTROP, Leonardo. Dicionário alemão-português. 6 ed. Rio de Janeiro: Globo, 1984.

WITTE, Bernd. Walter Benjamin: uma biografia. Tradução de Romero Freitas. Belo Horizonte: Autêntica Editora, 2017. 